\title{
Dispute over digital music muzzles academic
}

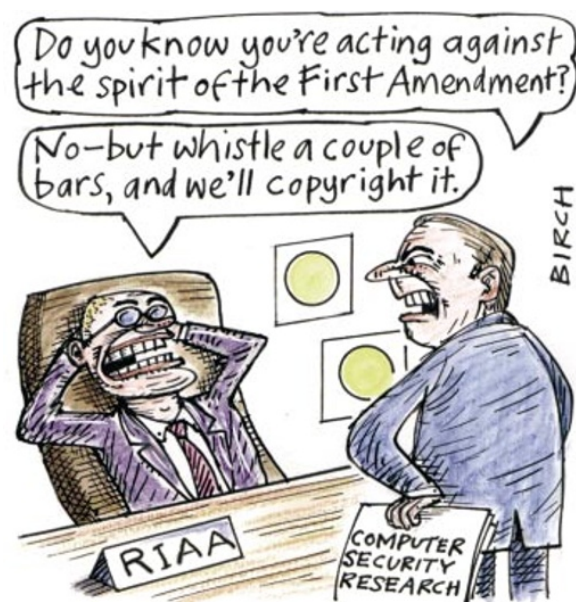

Corie Lok, Washington

A group of computer scientists has cancelled a conference presentation of a paper describing how they disabled anti-piracy systems for digital music, saying that they fear legal action by the recording industry.

Edward Felten, of Princeton University, and his colleagues withdrew their paper, which they had been due to present last week at the Fourth International Information Hiding Workshop in Pittsburgh, Pennsylvania, to avoid potential litigation. Felten said that he made the decision after failing to reach an agreement with representatives of the US recording industry.

"We remain committed to free speech and to the value of scientific debate to our country and the world," said Felten in a statement on 26 April, the day he was due to present the paper. "We will continue to fight for these values and for the right to publish our paper."

Later that day, the Secure Digital Music Initiative (SDMI), a consortium of recording and electronics companies that was co-founded by the Recording Industry Association of America (RIAA), released a statement saying that it did not and does not intend to bring legal action against Felten or his colleagues.

The dispute highlights the conflict between academic computer scientists, who claim that open investigation of weaknesses in security technology is necessary to improve protection in the long run, and the recording industry, which is trying to keep hackers from using this information to distribute copyrighted material.

In an attempt to detect possible shortcomings in copyright-protection measures, the SDMI challenged the public last year to crack these technologies, at least one of which was commercially available. Felten and his colleagues entered the contest, although Felten says they pulled out early and surrendered any claim on the cash prize in order to publish their findings.
Their paper describes how they successfully defeated the 'watermarks' — signals that are encoded into copyrighted digital music to prevent unauthorized copying. Called 'Reading between the lines: lessons from the SDMI challenge', it was published without permission on a libertarian website (http://www.cryptome.org) a few days before the conference.

Another paper detailing one of the technologies from the SDMI contest was presented as scheduled at the conference by two French researchers.

In a letter to Felten earlier this month which also appeared on the Internet with the paper - Matthew Oppenheim, SDMI secretary and vice president of the RIAA, wrote that public disclosure of information gained from the contest could lead to unauthorized hacking of these technologies and would violate both the agreement signed by contest participants and possibly the 1998 Digital Millennium Copyright Act (DMCA).

Felten said in an e-mail, however, that he and his colleagues do not believe that their paper violates the agreement.

"The DMCA raises some serious First Amendment issues," says Lee Tien, an attorney with San Francisco-based civil liberties group the Electronic Frontier Foundation, referring to the section of the US Constitution that guarantees freedom of speech.

The DMCA outlaws public availability of

technology or devices designed to circumvent copyright-protection systems. "It is clear now that the DMCA is a serious impediment to computer-security research," says Felten, who declined to say whether he thought the release of his paper would have violated the DMCA.

Some computer scientists worry about the implications of the episode for their academic liberty. "I think to forbid the talk ... is a violation of academic freedom and does not

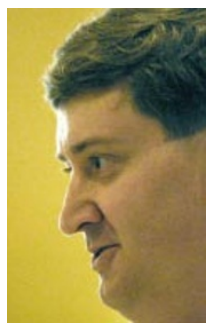

Show-stopper:

Felten withdrew his planned talk. bring us forward to finding improvements and better algorithms," says Jana Dittmann, a watermarking researcher at the German National Research Center for Information Technology in Darmstadt.

Computer scientists' organizations have spoken out against the DMCA, but a spokesperson for the Computer Society of the Institute of Electronics and Electrical Engineers declined to comment on the Felten dispute, saying it was a political matter.

Felten did not discuss his next step in trying to publish his paper formally. However, Steven Schultz, a spokesman for Princeton University, said: "Our researchers should be able to present their research to their colleagues and the world."

\section{Electronic ink for current issues}

\section{Declan Butler}

Imagine a copy of Nature that looks and feels just like today's printed issue but has a cover and pages that automatically change into the latest edition. At the touch of a stylus, the magazine could be transformed into any back issue stored in an archive in the spine.

This science-fiction scenario has moved a step closer with the announcement by E Ink, a company based in Cambridge, Massachusetts, that it has developed its first portable-computer-type display - a prototype of 'electronic paper'.

E Ink's technology consists of an ink made of tiny capsules that change colour when a small electric current is passed through them (see Nature 394, 253-255; 1998). Coat this electronic ink onto paper, and the sheet can produce high-resolution text and images that remain visible when the electricity is switched off.

Simple electronic-ink displays have already been produced, showing only a handful of characters. To display large volumes of text and images, the technology requires dense circuitry known as a backplane. Commercial development is limited by the lack of low-cost backplanes, says Barrett Comiskey, chief architect and co-founder of E Ink.

But the prototype display, developed by E Ink in collaboration with IBM, uses a new form of electronic ink to give the resolution of a laptop display. Because it looks like ink on paper, the screen is up to six times brighter than current laptop screens, and according to $\mathrm{E}$ Ink has better contrast than a newspaper, even in bright sunlight. Because it needs no backlight, the display uses onethousandth of the power required by most portable screens. Details of the design will be presented by IBM and E Ink at the Society for Information Display Conference in San Jose, California in June.

In a step towards the ultimate goal of producing electronic paper, E Ink and Lucent Technologies have also published work (Proc. Natl Acad. Sci. USA 98, 4835-4840; 2001) showing the potential of using lightweight plastic backplanes. 